\title{
Towards research-based learning outcomes for general practice in medical schools: Inaugural Barbara Starfield Memorial Lecture
}

\author{
Denis Pereira Gray, OBE, HonDSc, HonfAcadMedEd, FRCP, FRCGP, FMedSci, ${ }^{*}$ \\ Past Chair of Council and President, RCGP; Emeritus Professor; Consultant, St \\ Leonard's Research Practice, Exeter, UK
}

'... Medical schools should recognise they have a responsibility to patients to educate and prepare half of all graduates for careers in general practice ... Teaching and promotion of general practice as a career which is as professionally and intellectually rewarding as any other specialism. Those medical schools which do not teach primary care as a subject should be held to account by the General Medical Council.' ${ }^{1}$

'... It [general practice] is a really hard job. They GPs, have to be clinically, intellectually, and emotionally strong ... to identify major clinical problems masquerading as minor ailments and it is utterly relentless. It requires a lot of intellectual flexibility and people have to be very tolerant individuals. It is one of the hardest jobs in medicine. ${ }^{2}$

'... Health Education England is currently working with the Medical Schools Council, higher education institutions, the RCGP and the GPC to increase the profile of general practice in medical schools and in their curricula. A working group, chaired by Professor Valerie Wass OBE, will publish recommendations in Summer 2016 about recruitment and selection, finance and curriculum and the promotion of general practice as a specialty. ${ }^{3}$ (author's italics)

*For correspondence: denis. pereiragray@btinternet.com

Received: 11 August 2016 Accepted: 25 September 2016 Published: 09 January 2017

(c) This article is Open Access: CC BY license (https:// creativecommons.org/licenses/ by/4.0/)

Author Keywords: general practice, primary care, learning outcomes, curriculum,

undergraduate, medical schools

Copyright (C) The Authors 2017;

DOI:10.3399/

bjgpopen17X100569

\section{Studying the discipline of general practice}

These statements underline why medical students should study general practice as a specialty or specialism, that is as a distinct subject, and that this needs to be done intellectually, a word appearing three times in these extracts. 'Intellectual' is defined by the Oxford Dictionary as 'possessing a high level of understanding ...' implying understanding of general practice research.

An intellectual approach is needed as current medical students have been highly selected on intellectual criteria. They want know the 'hows and whys' of medicine. If they hear theory and principles only from hospital specialists, they will be drawn only to hospital practice and $81 \%$ of medical students currently do not see general practice as their first choice. ${ }^{4}$

The words 'primary care' are not used here, except in quotation, and 'general practice' is used. The meaning of primary care is unclear. It mixes community and hospital services, relationship and non-relationship-based services, and five different health professions. This curriculum is designed to help medical students understand and choose general practice, enthusiastically. The avoidance by medical schools of the words 'general practice' in their prospectuses and within their institutions is prejudicial, making it harder for medical students to choose general practice positively as a career and be proud of it.

\section{Learning in medical schools}

Despite calls for a UK core curriculum in general practice, ${ }^{5,6}$ none currently exists. There is confusion between general practice as a place for learning and as a discipline to be learned. 


\section{All students}

Medical schools prepare students for all branches of medicine. The GP curriculum should be provided within the medical school curriculum to all students, including those seeking hospital careers, so that all future doctors understand the theory and principles of general practice. The medical school's course, of at least 20 hours, should be integrated with teaching in the general practices, so that local GPs, well-briefed on the GP curriculum and with practice libraries and files of key articles, can demonstrate the integration of theory and practice. Some medical schools provide $20 \%$ of the undergraduate curriculum time in general practice, ${ }^{7}$ so $20 \%$ of the teaching resources of the medical school should follow.

\section{Learning about general practice as an independent discipline}

The theory and principles of general practice should not be confused with students learning about the diseases seen in general practice. The diseases are usually learned well, whereas general practice as a distinct subject is usually not learned at all.

\section{Teaching a subject or university discipline}

A discipline requires a defined body of knowledge ${ }^{8}$ and for universities and medical schools, this knowledge is published in peer-reviewed journals. ${ }^{9}$

A modern curriculum must source its statements, so learners and teachers are linked repeatedly with relevant research: research-based teaching is fundamental.

The reading list of the Tamar Faculty of the Royal College of General Practitioners could be built on. ${ }^{10}$ This is the first set of referenced, that is research-based, learning outcomes collectively forming a GP curriculum, which should be delivered within the medical school's overall curriculum. While incomplete, it offers a start in fostering development.

\section{Teaching and assessment within the medical school}

The GP curriculum should be taught within the medical school, not outsourced. If in 5 years of higher education, medical students see nothing positive about general practice in the medical school's prospectus, see no GP curriculum, no clear learning outcomes, no exciting GP reading-list, then the medical school is:

'... giving a powerful non-verbal signal that general practice is not important and that nothing

has been written from or about general practice that future doctors need to read! ${ }^{1}$

It is essential that examination and assessment systems in all UK medical schools reflect the importance of general practice, so $20 \%$ of examination questions should be on the theory and principles of general practice.

\section{Theory and principles of general practice: learning outcomes}

\section{Facts about general practice}

Students need to understand the scale and importance of general practice. Students need to know the 'dozen facts about general practice', ${ }^{11}$ which is the biggest and most important branch of the medical profession, managing $86 \%$ of the problems that the population brings to doctors and nurses ${ }^{12}$ on only $8.5 \%$ of the NHS budget. ${ }^{1}$ Its UK-wide Medical Royal College, has the biggest membership and the biggest annual income of the all the Medical Royal Colleges in the British Isles.

\section{First-contact care}

General practice is the front line of the NHS. ${ }^{13}$ Students should understand that GPs see patients with undifferentiated illness in any part of the body or mind. A big challenge is 'major illness masquerading as minor illness. ${ }^{2}$ Presenting symptoms in general practice can be physical, psychological, or both and are heavily influenced by the social determinants of illness, ${ }^{14}$ which GPs see first-hand in individual patients more than any other doctor. 
Culture affects what is perceived as illness, how illness presents, and why some treatments may cause difficulties for some cultural groups. Helman, a GP Professor of Anthropology, wrote classic books on culture and health. ${ }^{15,16}$

\section{Diagnoses}

Medical students should understand that general practice is where most diagnoses are made. Some diagnoses are never or rarely made in hospitals. Students should understand the importance of making diagnoses, their value for treatment and prognosis, and the reassurance diagnosis gives patients. Students should also understand the adverse-effects of diagnoses, including labelling and stigma for some patients.

Diagnoses in general practice are made under time pressure and with fewer investigations available. Errors occur. One study found $9.4 \%$ of primary care diagnoses were wrong. ${ }^{17}$ Students should learn how to reduce this.

\section{Human behaviour}

Students need to learn to think about patients in terms of behaviour as well as pathology. One of the main reasons why general practice differs from hospital practice is the importance of human behaviour by patients, families, and doctors. Feelings loom large.

Research on the behaviour of patients before the consultation ${ }^{18,19}$ during the consultation $^{20,21}$ and compliance after the consultation ${ }^{22}$ needs to be understood. How do doctors build a 'sustained partnership with patients' ${ }^{23}$ and achieve patient-centred consulting? ${ }^{24}$ How do such medical behaviours affect medical outcomes ${ }^{25}$ Many difficult diagnoses, like pathologicallyunexplained symptoms, and many management problems in general practice are behavioural.

GP thinking first conceptualised human behaviour as infectious, ${ }^{26}$ which has been supported by dramatic recent research. ${ }^{27,28}$

\section{Medical generalism}

Mens sana in corpore sano (a sound mind in a sound body). Both the ancient Greeks and the Romans understood that body and mind are closely interrelated, as has been confirmed by recent research. $^{29}$

GPs are unique in being the only doctors who accept both problems of the mind and the body simultaneously. For over 200 years, they have successfully resisted the separation of body and mind, often into separate hospitals, which is the great flaw in specialist medicine, worldwide. Medical generalists take the widest view of the patient and alone can see their patients and their illnesses in context. $^{30}$ It is a great advantage for patients to feel understood and to have, say, depression and diabetes, diagnosed and treated in a single consultation.

Students should understand the comparative advantages and disadvantages of generalist and specialist care. This should include research showing better outcomes by specialists than generalists, ${ }^{31}$ research where NHS GPs matched consultant psychiatrists for depression ${ }^{32}$ and US family physicians matched orthopaedic specialists for backache, ${ }^{33}$ and research where GPs outperformed specialist mental health services in detecting suicide risk. ${ }^{34}$

\section{Continuity of care}

Continuity is the 'mortar that holds general practice care together' (Bradley, NCA [2015]); personal communication). Medical students should understand research showing that continuity of care benefits patients through better quality care, ${ }^{35}$ and reducing emergency hospital admissions ${ }^{36}$ and even mortality. ${ }^{37}$ Doctors benefit by working with more satisfied, ${ }^{38}$ trusting, $^{39}$ and compliant, patients. ${ }^{40}$

Continuity benefits society through better uptake of preventive medicine, ${ }^{41}$ fewer hospital admissions, ${ }^{36}$ and lower-cost health systems. ${ }^{42,43}$ Students should understand the adverse effects of continuity, like dependency. ${ }^{44}$

\section{Family care}

The commonest name for GPs worldwide is 'family physician'. Many illnesses are familial: alcoholism, several common cancers (including breast and prostate), depression, diabetes, epilepsy, glaucoma, ischaemic heart disease, obesity, several rheumatic conditions, and schizophrenia. Family doctors 
knowing the family history can diagnose more quickly and are better at risk assessment. Most couples with children register with the same general practice, so students should understand this unique potential for medical care. Huygen's classic Family Medicine stated that 'the family is the unit of care. ${ }^{45}$ Students should understand the privilege of family doctors having several family members as patients simultaneously and caring across generations.

Students should appreciate the arithmetic of English GP consultation rates. The average patient contacts their general practice 5.2 times per annum, seeing a GP face-to-face three times a year. ${ }^{46}$ Therefore, a four-person household will see a GP on average 12 times a year. Assuming 10minute consultations, this means 2 hours per annum. If GPs group families on personal lists, ${ }^{47}$ they have plenty of time to get to know their patients as people. Otherwise, consultations are dispersed between different doctors.

When I retired from clinical practice, $7 \%$ of my personal list (averaging one patient in every surgery session) had a four-generational relationship with me: a baby, one or more parent, one or more grandparents, and one or more great grandparents registered simultaneously. It's a rich experience being a real family doctor.

\section{Personal preventive care}

Preventing illness is the doctor's 'supreme objective'. ${ }^{26}$ General practice uniquely integrates preventive medicine with curative medicine. Students should appreciate how much primary preventive care GPs provide to registered populations and symptom-free people.

Secondary prevention includes detecting conditions before symptoms arise; for example, abnormal cervical smears and hypertension.

GPs are the experts in identifying and minimising risk factors for disease; for example, detecting and treating high blood pressure and raised cholesterol for millions. Such clinical opportunistic screening, a cost-effective process, has helped to halve UK heart attacks in the last decade. ${ }^{48}$

Students should understand that tertiary prevention, the prevention of complications of existing disease, is a central part of GP work with computerised risk assessment for cardiovascular disease routine. General practice more than any other branch of medicine provides the greatest opportunities for health promotion.

\section{Care in the patient's home}

Homes influence the health and happiness of those living there. One model of the consultation is the GP should understand: 'what the patient is feeling at home. ${ }^{26}$ Working comfortably in patients' homes is a skill to be learned and how homes influence the origin of disease and the ability of people to manage illness there. Patients disclose information more freely at home and rapport points can facilitate care. ${ }^{49}$

It is usually only in homes that GPs see family groups together; for example, seeing a grandmother or lodger, influencing family dynamics. For disabled people and the dying, home visiting is especially important.

\section{Care in the community}

GPs are the lead community clinicians with unrivalled opportunities to collaborate with other community-based services and voluntary groups. While hospitals are distant from many homes, only $1 \%$ of English city dwellers live more than 2 kilometres away from a general practice, ${ }^{1}$ so most practices are within 'pram-pushing' distance.

\section{Patient-centred medicine}

In the medical profession general practice is best placed to achieve patient-centred care. The aim in medicine is to understand and treat each patient as a person. Generalist doctors can best integrate the widest range of medical conditions, the patient's psychological state, and often relevant social factors. Getting to know patients as people is much easier in general practice.

Doctors should understand each patient's 'concerns, ideas, and expectations. ${ }^{50}$ To provide highquality personal care the doctor must understand the patient's hopes and fears and how illness affects them. It requires skill to gather this information and repeated consultations with the same patient are how valuable 'accumulated knowledge ${ }^{\prime 51}$ is gained. 


\section{Patient-doctor relationships}

General practice has the longest and deepest working relationships with patients. Students should understand that good patient-doctor relationships are particularly important in general practice and that not all doctors are suitable for general practice. ${ }^{20}$

GPs must be tolerant and flexible to meet the needs of their patients. GPs alone define their medical role through relationships with patients. ${ }^{30}$ Students should reflect on how such relationships are created and maintained. After 20 consultations with the same doctor, about $80 \%$ of patients consider their relationship with their family doctor is 'deep'. ${ }^{52}$

Students should know the benefits of strong patient-doctor relationships and their adverseeffects, like dependence. Students should understand contextual healing (placebo effect) ${ }^{53}$ and how it can extend effectiveness in general practice.

\section{Empathy}

Doctors in histopathology, accident and emergency medicine, and urgent-care centres, have chosen relatively relationship-free settings. But, empathy matters in general practice, which is different. ${ }^{54}$ Medical students should know the systematic review indicating that their empathy levels on average decline as they progress through medical school ${ }^{55}$ and what can be done about it. ${ }^{56}$

Students should know that general practice provides the longest and richest patient-doctor relationships in medicine. The median duration of registration of the 8800 patients in my former practice in 2016 is 7.1 years and the upper quartile of patients have been registered for 18.9 years. ${ }^{57}$

\section{Biographical approach}

General practice fosters the biographical approach to medicine, such as understanding significant life-events ${ }^{58}$ and the adverse effects of childhood abuse. ${ }^{29}$ These enable GPs to understand both the antecedents of much ill health and their patients as people.

\section{Narrative medicine}

Patients mainly communicate verbally with doctors through particular words and metaphors. While all doctors use narrative medicine, generalists have studied it most, ${ }^{59-61}$ and the widest applications are in general practice.

\section{Cost-effectiveness}

Medical students should understand why general practice is exceptionally cost effective. Primary care orientated health systems have lower overall costs. ${ }^{42}$ Healthcare costs are influenced by the values of sites, buildings, and equipment. Hospital services through their overheads are more expensive than general practice. Students should understand how GPs manage $86 \%{ }^{62}$ of the medical needs of the population on (in 2013-2014) only $8.2 \%^{63}$ of the English health budget.

A single outpatient appointment with an English Consultant Diabetologist cost $f 222$ in $2015 .{ }^{63}$ The cost of a GP appointment in 2015 was $f 37,{ }^{64}$ an appointment in a nurse-led clinic was $f 39$ in $2010-2011,{ }^{65}$ and an ambulance attending a home in 2015 cost $f 231 .{ }^{66}$ Students should understand why general practice takes pride in its cost efficiency.

\section{Population medicine - the registered list}

General practice alone has a precisely-known population with characteristics like age, sex, and social deprivation available. A British GP was the first doctor in the world to go online with a medical record. ${ }^{67}$ For the most IT literate generation of medical students, GP computing, the most sophisticated in the English NHS, offers rich opportunities for quality assurance, education, and research.

\section{Practice management}

Most GPs are independent contractors, uncommon in the NHS, but the norm for community professionals. ${ }^{68}$ Partnership working is a good model for partnership working with patients. Partnership is a privilege, giving locus of control ${ }^{69}$ and flexibility which, with the absence of hierarchies means that half of female GPs have their first baby by age 32 years, whereas less than half the female doctors in anaesthetics, general medicine, and surgical specialties, have their first baby by age 35 years. ${ }^{70}$ This 3 -year difference is highly significant for women in their 30 s. Salaried doctors 
are in a 'master-servant' relationship ${ }^{71}$ hence GP partners, unlike salaried hospital consultants, do not have gagging clauses in their contracts.

\section{Patient satisfaction}

General practice patients are more satisfied with 'Your GP' than hospital inpatients or outpatients. $^{72}$ They are also far more satisfied than with consultations in accident and emergency departments. $^{73}$

\section{Reducing socioeconomic disadvantage}

Inequality and health inequalities are one of the biggest challenges of our time. Social deprivation is associated with higher rates of illness and deaths. The mortality rate for men in routine occupations is almost three times higher than men in professional work. ${ }^{74}$ Students should know why hospitals are 'pro rich' and general practice is 'equitable.' ${ }^{75}$ and how GPs, more than other clinicians, can ameliorate social disadvantage. ${ }^{76-78}$

Medical students and junior doctors have strong social consciences and many entered medicine to help people. General practice is the clinical setting where more can be done for more people than anywhere else.

\section{Reducing mortality}

Death is the 'hardest' of all outcomes. 'Each additional family physician is associated with 34 lives saved per 100000 citizens. $^{179}$ More lives are saved in general practice than by any other branch of medicine.

\section{GP education}

General practice is quietly taking the lead in UK medical education. As early as the 1970s, general practice, alone, required GP trainers to be trained as teachers and dismissed trainers if they underperformed. ${ }^{80}$ Junior doctors reporting on their training, rank general practice highest. ${ }^{81}$ There is an unacceptable amount of bullying of junior doctors in specialist training. ${ }^{82}$ The two branches of medicine where the patient's feelings are central on the doctor's professional agenda, general practice and psychiatry, had the least bullying. General practice was best of all. Thirdly, the General Medical Council survey of work-based placements in medicine, found those in general practice were ranked highest. ${ }^{83}$

However, a collective blind spot in reading research in both undergraduate and postgraduate GP education exists. Only when this is rectified, will GP education consolidate its leading position.

\section{Career opportunities}

Most children never see a paediatrician after newborn checks. Most older people never see a geriatrician. Most mentally ill patients never see a psychiatrist, and most people with diabetes never see a diabetologist. Yet GPs see all of these patients, every week.

General practice has at last been recognised as the central discipline in medicine. It is now the top priority for medical careers in the UK, with half of all postgraduate training places reserved for it. ${ }^{1}$

\section{Conclusion}

The recommendation of the UK Parliament ${ }^{1}$ in April 2016 that primary care and general practice be taught in UK medical schools 'as intellectually rewarding' and 'as a subject' was historic and the most important event in undergraduate general practice teaching since 1948. The second step is agreeing what is to be taught in UK medical schools, hence this research-based curriculum. The third remaining step will be assessing these learning outcomes.

Provenance

Freely submitted; externally peer reviewed. 


\section{Acknowledgments}

The inaugural Barbara Starfield Lecture was initiated and chaired by Professor Jose Valderas-Martinez in the University of Exeter Medical School, Exeter and was delivered in September 2015. This article has been derived from it. I acknowledge with gratitude Drs Philip Evans and Alexander Harding, Managing Partners St Leonard's Practice Exeter, for encouragement and support, Dr Kate Sidaway-Lee for editorial help, and $\mathrm{Dr}$ Anne Stephenson, a $\mathrm{Br} J$ Gen Pract Open reviewer, for valuable suggestions.

\section{Addendum}

Since this article was accepted for publication, the report of the Wass Committee has been published.

Wass Committee (2016) By Choice not by Chance Supporting medical students towards future careers in general practice. Chair, Professor Valerie Wass. London: Medical Schools Council and Health Education England.

It includes a paragraph:

"Formal teaching on the core knowledge and skills which distinguish general practice as a specialty distinct from those of broader generalist practice is needed." P28. [Author's emphasis].

\section{References}

1. Wollaston Committee. Primary Care. Report of the Health Select Committee of Parliament Chair. Dr Sarah Wollaston (Paragraphs 143 and 144). London: House of Commons, 2016.

2. Keogh B. Evidence to the Wollaston Committee. Primary Care. London: House of Commons, 2015.

3. NHS England. General Practice Forward View. London: NHSE, 2016.

4. Lambert T, Goldacre M. Trends in doctors' early career choices for general practice in the UK: longitudinal questionnaire surveys. Br J Gen Pract 2011; 61(588): 397-403. doi: 10.3399/bjgp11X583173

5. Oswald NT, St J Alderson T. A core curriculum in general practice. Med Educ 1997; 31(5): 352-353. doi: 10. 1046/j.1365-2923.1997.00679.x

6. Blythe A, Hancock J. Time for a national undergraduate curriculum. Br J Gen Pract 2011; 61(591): 628.

7. Harding A, Rosenthal J, Al-Seaidy M, et al. Provision of medical student teaching in UK general practices: a cross-sectional questionnaire study. Br J Gen Pract 2015; 65(635): e409-e417. doi: 10.3399/bjgp15X685321

8. McWhinney IR. General practice as an academic discipline. Reflections after a visit to the United States. Lancet 1966; 1(7434): 419-423.

9. Pereira Gray D. McConaghey memorial lecture 1988. The emergence of the discipline of general practice, its literature, and the contribution of the College Journal. J Roy Coll Gen Pract 1989; 39(323): 228-233.

10. RCGP Tamar Faculty. Short Reading List for Medical Students. Tamar Faculty: Exeter, 2015.

11. Pereira Gray D. A Dozen Facts about General Practice. Updated Version of an Appendix to the White Paper Our Health, Our Care, Our Say. London: Department of Health.

12. Office of Population Censuses and Surveys. General Household Survey. London: OPCS, 1991.

13. Royal College of General Practitioners. The Front Line of the NHS Report From General Practice No 25. London: RCGP, 1987.

14. Marmot M. Social determinants of health inequalities. Lancet 2005; 365(9464): 1099-1101. doi: 10.1016/ S0140-6736(05)74234-3

15. Helman C. Suburban Shaman: Tales From Medicine's Frontline. London: Hammersmith Press, 2006.

16. Helman C. Culture Health and Illness. 5th edn. London: Taylor Francis, 2007.

17. Singh $H$, Thomas EJ, Khan $M M$, et al. Identifying diagnostic errors in primary care using an electronic screening algorithm. JAMA Int Med 2007; 167(3): 302-308. doi: 10.1001/archinte.167.3.302

18. Robinson D. The Process of Becoming III. London: Routledge and Kegan Paul, 1971.

19. Stimson G, Webb B. Going to See the Doctor: The Consultation Process in General Practice. London: Routledge and Kegan Paul, 1975.

20. Balint M. The Doctor His Patient and the Illness. London: Tavistock, 1957.

21. Thomas KB. General practice consultations: is there any point in being positive? BMJ 1987; 294(6581): 1200-1202. doi: 10.1136/bmj.294.6581.1200

22. Chen $\mathrm{CC}$, Tseng $\mathrm{CH}$, Cheng SH. Continuity of care, medication adherence, and health care outcomes among patients with newly diagnosed type 2 diabetes: a longitudinal analysis. Med Care 2013; 51(3): 231237. doi: 10.1097/MLR.0b013e31827da5b9

23. Leopold N, Cooper J, Clancy C. Sustained partnership in primary care. J Fam Pract 1996; 42(2): 129-137.

24. Stewart M, Belle Brown J, Weston W, et al. Patient-Centered Medicine. 2nd edn. Abingdon: Radcliffe Press, 2003.

25. Bertakis KD, Azari R. Patient-centered care is associated with decreased health care utilization. J Am Board Fam Med 2011; 24(3): 229-239. doi: 10.3122/jabfm.2011.03.100170

26. Pereira Gray D. James Mackenzie Lecture 1977. Feeling at home. J Roy Coll Gen Pract 1978; 28: 6-17. 
27. Christakis NA, Fowler JH. The spread of obesity in a large social network over 32 years. N Engl J Med 2007; 357(4): 370-379. doi: 10.1056/NEJMsa066082

28. Christakis NA, Fowler JH. The collective dynamics of smoking in a large social network. N Engl J Med 2008; 358(21): 2249-2258. doi: 10.1056/NEJMsa0706154

29. Anda RF, Felitti VJ, Bremer JD, et al. The enduring effects of abuse and related adverse experiences in childhood. A convergence of evidence from neurobiology and epidemiology. Eur Arch Clin Neuroscience 2005; 25: 174-186.

30. McWhinney IR. William Pickles Lecture 1996. The importance of being different. Br J Gen Pract 1996; 46 (408): 433-436.

31. Ayanian JZ, Landrum MB, Guadagnoli $E$, et al. Specialty of ambulatory care physicians and mortality among elderly patients after myocardial infarction. N Engl J Med 2002; 347(21): 1678-1686. doi: 10.1056/ NEJMsa020080

32. Scott Al, Freeman CP. Edinburgh primary care depression study: treatment outcome, patient satisfaction, and cost after 16 weeks. BMJ 1992; 304(6831): 883-887.

33. Carey TS, Garrett J, Jackman A, et al. The outcomes and costs of care for acute low back pain among patients seen by primary care practitioners, chiropractors, and orthopedic surgeons. The North Carolina Back Pain Project. N Engl J Med 1995; 333(14): 912-917. doi: 10.1056/NEJM199510053331406

34. Pearson A, Saini $P, D a$ Cruz D, et al. Primary care contact prior to suicide in individuals with mental illness. $B r$ J Gen Pract 2009; 59(568): 825-832. doi: 10.3399/bjgp09X472881

35. Campbell SM, Hann M, Hacker J, et al. Identifying predictors of high quality care in English general practice: observational study. BMJ 2001; 323(7316): 784-786.

36. Menec $\mathrm{VH}$, Sirski M, Attawar $\mathrm{D}$, et al. Does continuity of care with a family physician reduce hospitalizations among older adults? J Health Serv Research Policy 2006; 11(4): 196-201. doi: 10.1258/ 135581906778476562

37. Worrall G, Knight J. Continuity of care is good for elderly people with diabetes: retrospective cohort study of mortality and hospitalization. Can Fam Physician 2011; 57(1): e16-20.

38. Baker R, Mainous AG 3rd, Pereira Gray D, et al. Exploration of the relationship between continuity, trust in regular doctors and patient satisfaction with consultations with family doctors. Scand J Prim Health Care 2003; 21(1): 27-32. doi: 10.1080/0283430310000528

39. Mainous AG, Baker R, Love MM, et al. Continuity of care and trust in one's physician: evidence from primary care in the United States and the United Kingdom. Fam Med 2001; 33(1): 22-27.

40. Ettlinger PR, Freeman GK. General practice compliance study: is it worth being a personal doctor? $\mathrm{Br} \mathrm{Med} \mathrm{J}$ 1981; 282(6271): 1192-1194. doi: 10.1136/bmj.282.6271.1192

41. Blewett LA, Johnson PJ, Lee $B$, et al. When a usual source of care and usual provider matter: adult prevention and screening services. J Gen Intern Med 2008; 23(9): 1354-1360. doi: 10.1007/s11606-0080659-0

42. Starfield B. Is primary care essential? Lancet 1994; 344(8930): 1129-1133.

43. Baicker K, Chandra A. Medicare spending, The physician workforce, and Beneficiaries' quality of care. Health Affairs 2004; W4: 184-197. doi: 10.1377/hlthaff.w4.184

44. Pereira Gray D, Sidaway-Lee K, Thorne A, et al. Improving continuity - The clinical challenge. InnovAiT 2016; doi: 10.1177/1755738016654504

45. Huygen FJA. Family Medicine. The Medical Life History of Families. London: Republished RCGP, 1978.

46. Hobbs FD, Bankhead C, Mukhtar T, et al. Clinical workload in UK primary care: a retrospective analysis of 100 million consultations in England, 2007-14. Lancet 2016; 387(10035): 2323-2330. doi: 10.1016/S01406736(16)00620-6

47. Pereira Gray D. The key to personal care. J Roy Coll Gen Pract 1979; 29(208): 666-678.

48. Smith R. Heart attack deaths halved by statins and healthier living. Daily Telegraph 2012;26th December.

49. Whitaker P. Health matters. My Patient refused to go into hospital - and then I saw the poster on the wall. New Statesman 19 May 2016.

50. Silverman J, Kurtz S, Draper J. Skills for Communicating with Patients. 3rd edn. Abingdon: Radcliffe Publishing, 2013.

51. Hjortdahl P. Continuity of care: general practitioners' knowledge about, and sense of responsibility toward their patients. Fam Pract 1992; 9(1): 3-8.

52. Ridd MJ, Lewis G, Peters TJ, et al. Patient-doctor depth-of-relationship scale: development and validation. Ann Fam Med 2011; 9(6): 538-545. doi: 10.1370/afm.1322

53. Kaptchuk TJ, Miller FG. Placebo Effects in Medicine. N Engl J Med 2015; 373(1): 8-9. doi: 10.1056/ NEJMp1504023

54. Jeffrey D. Clarifying empathy: the first step to more humane clinical care. Br J Gen Pract 2016; 66(643): e143-e145. doi: 10.3399/bjgp16X683761

55. Neumann M, Edelhäuser F, Tauschel D, et al. Empathy decline and its reasons: a systematic review of studies with medical students and residents. Acad Med 2011; 86(8): 996-1009. doi: 10.1097/ACM. Ob013e318221e615

56. Hirsh DA, Holmboe ES, Ten Cate O. Time to trust: longitudinal integrated clerkships and entrustable professional activities. Acad Med 2014; 89(2): 201-204. doi: 10.1097/ACM.0000000000000111

57. White ES, Pereira Gray D, Langley $P$, et al. Fifty years of longitudinal continuity in general practice: a retrospective observational study. Fam Pract 2016; 33(2): 148-153. doi: 10.1093/fampra/cmw001

58. Brown GW, Harris T. The Social Origins of Depression. London: Tavistock. 
59. Greenhalgh T, Hurwitz B. Narrative based medicine: why study narrative? BMJ 1999; 318(7175): 48-50. doi: 10.1136/bmj.318.7175.48

60. Charon R. Narrative medicine: a model for empathy, reflection, profession and trust. JAMA 2001; 313(18): 1825-1826.

61. Pal K. The Art of Medicine: could you wait a second? Lancet 2016; 387: 1900-1901.

62 OPCS. General Household Survey. London: HMSO, 1998.

63. Everington S, Roland M. NHS England provides a major boost for general practice. BMJ 2016; 353:i2357.

64. National tariff payment system 2014/15 Internet. Monitor and NHS England 2013 - cited 25 May 2016. https://www.gov.uk/government/publications/national360tariff-payment-system-2014-to-2015.

65. Wheeler B. Are NHS walk-in centres on the way out? BBC News. 28 June 2012; http://www.bbc.co.uk/news/ uk-politics-18503034.

66. Curtis L, Burns A. Unit Costs of Health and Social Care. PSSRU Kent: University of Kent, 2015.

67. Preece JF, Gillings DB, Lippman ED, et al. An on-line record maintenance and retrieval system in general practice. Int J Biomed Computing 1970; 1(4): 329-337. doi: 10.1016/0020-7101(70)90006-1

68. Pereira Gray D. General practitioners and the independent contractor status. J Roy Coll Gen Practit 1977; 27(185): 746-749.

69. Mallaston BS, Wallaston KB, Kaplan GD, et al. Development and validation of the health locus of control (HLC) scale. J Consulting and Clinical Psychology 1976; 44(4): 58-85.

70. Goldacre MJ, Davidson JM, Lambert TW. Doctors' age at domestic partnership and parenthood: cohort studies. J Roy Soc Med 2012; 105(9): 390-399 Table 5. doi: 10.1258/jrsm.2012.120016

71. Court of Appeal. Times Law Report 5 November 1977.

72. Wanless D. Securing our Future. Interim Report Chart 7. London: HM Treasury, 2002.

73. Smyth C. Almost half of patients unhappy with A \& E. Times 7 May 2014;

74. Drever F, Whitehead M, Roden M. Current patterns and trends in male mortality by social class (based on occupation). Population Trends 1996; 86(86): 15-20.

75. Dixon A, Le Grand J, Henderson J, et al. Is the British National Health Service equitable? The evidence on socio-economic differences in utilization. J Health Serv Res and Policy 2007; 12(2): 104-109. doi: 10.1258/ 135581907780279549

76. Shi L. The relationship between primary care and life chances. Journal of Health Care for the Poor and Underserved 1992; 3(2): 321-335.

77. Shi L, Starfield B, Kennedy B, et al. Income inequality, primary care, and health indicators. J Fam Pract 1999; 48(4): $275-284$.

78. Starfield B, Shi L, Macinko J. Contribution of primary care to health systems and health. Milbank Quarterly 2005; 83(3): 457-502. doi: 10.1111/j.1468-0009.2005.00409.x

79. Starfield B. New paradigms for quality in primary care; keynote lecture to the NAPCRAG conference 2000. Br J Gen Pract 2001; 51: 303-309.

80 Pereira Gray D. Selecting general practitioner trainers. BMJ 1984; 288: 195-198.

81. Goldacre MJ, Davidson JM, Lambert TW. The first house officer year: views of graduate and non-graduate entrants to medical school. Medical Education 2008; 42(3): 286-293. doi: 10.1111/j.1365-2923.2007.02992.x

82. Paice E, Smith D. Bullying of trainee doctors is a patient safety issue. Clinical Teacher 2009; 6(1): 13-17. doi: 10.1111/j.1743-498X.2008.00251.x

83. General Medical Council. Survey of Doctors in Training. London: GMC, 2014. 